\title{
Factors Affecting Therapeutic Compliance among the Patients with Rheumatic Heart Disease in Bangladesh
}

\author{
Kakon Farzana1, Mohammad Omar Faruque ${ }^{2}$, Salma Zareen ${ }^{1}$, \\ Kamrun Nahar Choudhury ${ }^{1}$, Ahmed hossain ${ }^{2}$ \\ ${ }^{1}$ National Center for the Control of Rheumatic Fever and Heart Diseases, ${ }^{2}$ Department of Public \\ Health School of health and life sciences, North South University.
}

\begin{abstract}
Keywords:
Rheumatic

fever,

Rheumatic

heart disease,

Group A

Streptococcus,

Therapeutic

compliance.
\end{abstract}

\begin{abstract}
:
Background: Acute rheumatic fever $(A R F)$ can recur as a result of subsequent Group A Streptococcus $(G A S)$ infections and each recurrence can worsen Rheumatic heart disease (RHD) that has evoked a substantial disease burden in developing countries, including Bangladesh. The objective of this study was to determine the penicillin compliance for rheumatic fever patients.
\end{abstract}

Methods: A matched cross sectional study was conducted among 160 patients in National Center for the Control of Rheumatic Fever and Heart Diseases (NCCRF/HD), Dhaka. Data was collected on face-to-face interview using a standard structured questionnaire about socio-demographic, clinical and behavioral factors. Descriptive and multivariate logistic regression analyses were used to analyze the data.

Results: The multiple logistic regression analyses indicated that duration of diagnosis $>5$ beyond the duration of diagnosis $<5$ years $(O R=2.484, C I=1.170-5.421)$, age $(O R=0.548, C I=0.217-0.574)$, sex $(O R=0.916$, $C I=0.422-1.964)$, education ( $O R=1.963, C I=0.737-05.361)$, marital status(OR=0.700, $C I=0.272-1.774)$, fathers education (OR=0.482 CI=0.176 -1.279) and family member $(O R=0.619 C I=0.297-1.261)$ were significantly or almost significantly associated with RHD status.

Conclusion: In this study, the identified risk groups for rheumatic heart disease reflect a complex interaction between socioeconomic conditions and chronic disease status. Interventions focused on education and poverty will undoubtedly be useful, but not sufficient. Rheumatic heart disease control would benefit from a collaboration of broad public health activities aimed at the prevention and control other chronic diseases. The integration of rheumatic heart disease control activities with non communicable disease programme is crucial in Bangladesh.

(Cardiovasc. j. 2018; 10(2): 180-185)

\section{Introduction:}

Acute rheumatic fever is the result of an autoimmune response to pharyngitis caused by infection with the sole member of the group A Streptococcus, Streptococcus pyrogenes. ARF leads to an illness that is characterized by various combinations of joint pain and swelling, cardiac valvular regurgitation with the potential for heart failure, chorea, skin and subcutaneous manifestations and fever. The clinical manifestations of ARF are summarized in the recently updated Jones Criteria for the diagnosis of $\mathrm{ARF}^{1}$ and the most common clinical presentations are- Large joint arthritis and/or arthralgia, usually with fever, and sometimes with pan systolic murmur of mitral regurgitation. Although most of the clinical features of ARF will resolve during this short hospital stay, the cardiac valvular damage might persist. This chronic valvular damage is known as rheumatic heart disease (RHD) and is the major cause of morbidity and mortality from ARF.

ARF can recur as a result of subsequent GAS infections and each recurrence can worsen RHD. Thus, the priority in disease management is to prevent ARF recurrences using long-term penicillin treatment, which is known as secondary prophylaxis. The major advances in $\mathrm{ARF}$ and RHD treatment and control arose during the mid-twentieth century when these diseases were still common in North America. This period was the 'heyday' of ARF and RHD research and confirmed that penicillin treatment of GAS pharyngitis can prevent subsequent ARF (the basis of primary prophylaxis) and resulted

Address of Correspondence: Dr. Kakon Farzana, National Center for the Control of Rheumatic Fever and Heart Diseases, Dhaka, Bangladesh. Email: kakonfarjana@yahoo.com 
in trials confirming the efficacy of benzathine penicillin $\mathrm{G}$ for secondary prophylaxis; ${ }^{2,3}$ both of these interventions remain the cornerstones of disease management.

The incidence of initial cases of ARF is highest in children aged 5-14 years, although first episodes do occur in younger children, with reported cases of ARF in those as young as 2-3 years old. ${ }^{5,6}$ Initial episodes can also occur in older adolescents and adults, although cases in people $>30$ years of age are rare. By contrast, recurrent episodes often affect slightly older children, adolescents and young adults but are rarely observed beyond the age of 35-40 years. RHD is a chronic disease caused by accumulated heart valve damage from a single severe or, more commonly, multiple recurrent ARF episodes. This means that, although RHD occurs in children, its prevalence peaks in adulthood, usually between the ages of 25 years and 45 years. ${ }^{5}$

In addition, these sex differences might be stronger in adolescents and adults than in children. ${ }^{5,7}$ Regular administration of antibiotics to children who have had rheumatic fever is effective in reducing the number of recurrences of this disease.

This study was undertaken to determine penicillin compliance for rheumatic fever patients who received free penicillin through a countrywide prophylaxis program. It also investigated various medical, educational, behavioral, and social factors possibly related to compliance rates. Finally, an attempt to improve the compliance for penicillin through a reinforcement procedure was evaluated.

\section{Methods:}

This cross sectional study was conducted in NCCRF/HD, Dhaka, Bangladesh. Given 5\% significance level and $80 \%$ power, the calculated sample size was 160 . Consecutive samples were drawn until the sample sizes were achieved and the participants were selected in a purposive sampling scheme. The individuals had to be aged 18 years or above in order to eligible for this study.

Data was collected via an in-person interview, using a standard structured questionnaire that questions about important socio-demographic characteristics such as: date of birth, gender, marital status, education, family size, duration of diagnosis. Complete questionnaires were reviewed for quality assurance purpose. Written informed consent was obtained from each participant.

$\mathrm{R}$ software was used to analyze the data. The responses to the questionnaires were classified into categorical variables and continuous variables. The descriptive statistics were calculated for all the variables, including mean, standard deviation, frequencies, and percentages. The results were expressed in terms of their adjusted odds ratio (OR) and corresponding confidence intervals (CI) at $95 \%$. Independent factors associated with rheumatic heart disease were established using the multivariate logistic regression analysis.

\section{Results:}

The data comprised 160 Rheumatic Heart Disease patients aged 18 years or above. They gave their consent to participate in the study. We found 90 patients was non compliant and 70 patients was compliant according to Chinese version Morisky Medication Adherence Scale 8 -item.

Morisky Medication Adherence Scale (8-item)

\begin{tabular}{|c|c|c|}
\hline Item No. & Item & Answer $($ Yes $=1$, No. $=0)$ \\
\hline 1. & Do you sometimes forget to take your medication(s)/ Penicillin? & \\
\hline 2. & Over the past 2 weeks were there any days when you did take your medicine/Penicillin & \\
\hline 3. & $\begin{array}{l}\text { have you ever cut back or stopped taking your medication(s)/Penicillin without telling } \\
\text { your doctor, because you felt worse when you took it? }\end{array}$ & \\
\hline 4. & $\begin{array}{l}\text { When you travel or leave home, do you sometimes forget to bring along your chronic } \\
\text { medication(s)? }\end{array}$ & \\
\hline 5 . & Did you take your medication(s)/Penicillin yesterday? & \\
\hline 6. & $\begin{array}{l}\text { When you feel like your rheumatic fever is under control, do you sometimes stop taking } \\
\text { your medication(s)/Penicillin? }\end{array}$ & \\
\hline 7. & $\begin{array}{l}\text { Taking medication(s) every day is a real inconvenience for some people. Do you ever } \\
\text { feel hassled about sticking to your treatment plan? }\end{array}$ & \\
\hline 8. & $\begin{array}{l}\text { How often do you have difficulty remembering to take all your rheumatic } \\
\text { fever medication(s)/Penicillin? }\end{array}$ & \\
\hline
\end{tabular}

(Morisky Medication Adherence scale (MMAs-8-item). from Donald e Morisky, Professor, Department of community health sciences, UCLA School of Public health, 650 Charles E Young Drive south, Los Angeles, CA 90095-1772, USA.) 
In the Bar diagram shows the medication adherence scale (measuring by Morisky questions), $70 \%$ participants forget to take their medicine (question-1); 30\% respondents over the past 2 weeks were there any days when they forget take their medicine (question-2); 70\% patients cutback or stopped taking their medication (question-3); 50\% respondents forget to bring when they travel or leave home (question 4); $90 \%$ participants taking their medicine yesterday (question 5); 30\% respondents stop their medication when they feel the disease is under control (question 6); 90\% participants feel hassled about sticking medication(s) every day is a real inconvenience (question-7) and 50\% respondents they often do you have difficulty remembering to take all their rheumatic fever medications (question 8).(figure-1)

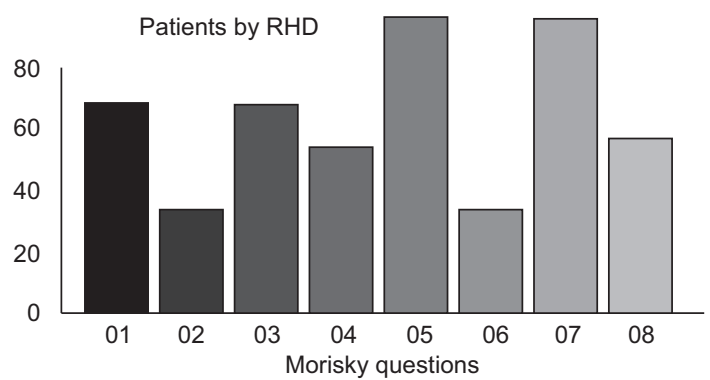

Fig.-1: Bar diagram of RHD patients by Morisky Medication Adherence Scale (8-Item).
Table I shows the socio-demographic factors associated with rheumatic heart disease (RHD) including: sex, education, marital status, father's education, mother's education, family members, duration of diagnosis were significantly associated with rheumatic heart disease status.

Table II shows clinical and behavioral factors associated with rheumatic heart disease along with their adjusted odds ratios. The risk factors include: gender, marital status, education, family size, duration of diagnosis were significantly associated with rheumatic heart disease.

A multivariate logistic regression model was fit after adjusting the extraneous variables, as illustrated in Table II. The RHD patients who are having duration of diagnosis $>5$ years $(\mathrm{OR}=2.484, \mathrm{CI}=1.170-5.421)$ are 2.484 times more likely to be treatment compliant compared to the patients who are having RHD less than duration of diagnosis 5 years.

Table-III depicts the relationship between rheumatic heart disease and other covariates after backward selection was performed on the multivariate logistic regression model. According to the backward selection analysis, completing duration of diagnosis $>5$ years was significantly associated (OR=2.405, CI=1.18 1-5.012) with being rheumatic heart disease negative. Patients

Table-I

Participant characteristics by treatment compliance and unadjusted association between each of covariates and treatment compliance.

\begin{tabular}{|c|c|c|c|c|c|}
\hline Variables & Categories & $\begin{array}{c}\text { Compliance } \\
\text { Yes }\end{array}$ & $\begin{array}{c}\chi^{2}-\text { value } \\
\text { No. }\end{array}$ & $p$-value & \\
\hline \multirow[t]{2}{*}{$\overline{\text { Age }}$} & $\geq 18$ yrs & 60 & 59 & 5.5 & 0.0187 \\
\hline & $<18$ yrs & 30 & 11 & & \\
\hline Sex & Male Female & 5535 & 4327 & 0 & 1.000 \\
\hline \multirow[t]{3}{*}{ Education } & $<5$ & 27 & 13 & 4.315 & 0.115 \\
\hline & $6-10$ & 37 & 27 & & \\
\hline & $>11$ & 26 & 30 & & \\
\hline \multirow[t]{2}{*}{ Marital status } & Married & 18 & 20 & 1.159 & 0.281 \\
\hline & Unmarried & 72 & 30 & & \\
\hline \multirow[t]{3}{*}{ Father's education } & $<5$ & 34 & 25 & 4.374 & 0.112 \\
\hline & $6-10$ & 22 & 27 & & \\
\hline & $>11$ & 34 & 18 & & \\
\hline \multirow[t]{3}{*}{ Mother's education } & $<5$ & 43 & 29 & 0.687 & 0.709 \\
\hline & $6-10$ & 23 & 21 & & \\
\hline & $>11$ & 24 & 20 & & \\
\hline \multirow{2}{*}{ Family members } & Joint & 48 & 41 & 0.251 & 0.616 \\
\hline & Nuclear & 42 & 29 & & \\
\hline \multirow[t]{2}{*}{ Duration of diagnosis } & $\leq 5$ & 45 & 18 & 8.737 & 0.003 \\
\hline & $>5$ & 45 & 52 & & \\
\hline
\end{tabular}


Table-II

Adjusted relationship between covariates and treatment compliance that is analyzed using logistic regression.

\begin{tabular}{lcccccc}
\hline Variables & Reference & Estimate & OR & LCL & UCL & p value \\
\hline Age (d" 18 years) & $>18$ & -0.60 & 0.54880 & 0.21730 & 1.3391 & 0.192 \\
$\begin{array}{l}\text { Sex (male) } \\
\text { Education (>11 class }\end{array}$ & Female & -0.87 & 0.91602 & 0.42287 & 1.9648 & 0.822 \\
$\quad<5$ & 0.674 & 1.96324 & 0.73738 & 5.3619 & 0.180 \\
$\quad \begin{array}{l}\text { Marital status } \\
\quad \text { (unmarried) }\end{array}$ & Married & -0.355 & 0.70073 & 0.27270 & 1.7743 & 0.454 \\
$\begin{array}{l}\text { Father's education (>11 } \\
\text { class and 6-10 class) }\end{array}$ & $\leq 5$ & -0.729 & 0.48237 & 0.17644 & 1.2793 & 0.147 \\
$\begin{array}{l}\text { Mother's education ( } \\
\quad>11 \text { class and 6-10 class) }\end{array}$ & $\leq 5$ & 0.320 & 1.37730 & 0.54528 & 3.4731 & 0.495 \\
$\begin{array}{l}\text { Family members } \\
\text { (nuclear ) }\end{array}$ & Joint & 0.691 & 1.99704 & 0.75457 & 5.4785 & 0.169 \\
$\begin{array}{l}\text { Duration of diagnosis } \\
\text { (>5 years) }\end{array}$ & $\leq 5$ & 0.479 & 0.61908 & 0.29743 & 1.2614 & 0.191 \\
\hline
\end{tabular}

Table-III

Backward selection between covariates and treatment compliance that is analyzed using logistic regression.

\begin{tabular}{lcccccc}
\hline Variables & Reference & Estimate & OR & LCL & UCL & p value \\
\hline Age $(18$ years $)$ & $>18$ & $(-) 0.7646$ & 0.46551 & 0.19589 & 1.0559 & 0.0729 \\
$\begin{array}{l}\text { Father's } \\
\text { education }(>11 \text { class }\end{array}$ & $<5$ & $>11(-) 0.2025$ & 0.81666 & 0.36353 & 1.8225 & 0.621 \\
$\begin{array}{l}\text { and 6-10 class) } \\
\begin{array}{l}\text { Duration of diagnosis } \\
(>5 \text { years })\end{array}\end{array}$ & $(6-10)-0.6556$ & 1.92621 & 0.86713 & 4.3733 & 0.110 \\
\hline
\end{tabular}

age $\geq 18$ years were also more significantly associated $(\mathrm{OR}=0.465, \mathrm{CI}=0.195-1.055)$ with being free of RHD, along with patients fathers education (6-10 class and $>11$ class) $(\mathrm{OR}=1.926$, $\mathrm{CI}=0.867-4.373, \mathrm{P}=0.110)$ and $(\mathrm{OR}=0.816$, $\mathrm{CI}=0.363-1.822 ; \mathrm{P}=0.621)$ were almost significantly associated with having RHD.

\section{Discussion:}

The study has assessed therapeutic compliance among patients with rheumatic heart disease in National Center for Control of Rheumatic fever and Heart disease, Dhaka, Bangladesh. The mean adherence was determined at $50 \%$. This was less than the adherence level determined by Harrington in an aboriginal community in Australia, in which $59 \%$ of patients had received more than $75 \%$ of their prescribed injections during an interview. ${ }^{8}$ Similarly the level of adherence we determined in this study was considerably less than that found among RHD patients in another Aboriginal community in Australia were the mean adherence level was $56 \%$ when patients were followed up for a period of 24 months. ${ }^{9}$ The variability in levels of adherence may reflect the different systems in which these studies were done, duration of follow up, the different factors that may influence adherence, the individual study designs, This variability is still hard to explain confidently since low levels of adherence have been demonstrated in Australia were rheumatic heart disease registries exist and are fully functional. During multivariate logistic regression analysis, patients with higher diagnosis duration ( $>5$ years) were more likely to be adherent compared to patients with lower diagnosis duration ( $<5$ years). This 
finding was similar to studies done in Canada, USA and Germany. ${ }^{10-13}$

Educational level was found not significant although it seems higher education related with higher adherence. Because patients who are more literate might have an updated information on the disease and its progression, and have a better understanding of the importance of adherence to the medications.

Analyzing the association of patient factors with adherence levels provides insight into those groups at particular risk of recurrence through poor adherence. No particular sociodemographic factor was found to be significantly associated with adherence. This was not surprising as a similar study by Stewart in Australia found no significant demographic factors associated with adherence ${ }^{5}$. However, trends towards adherence were demonstrated among patients who resided in a town/city.

The fact that patients who resided in a town/ city tended to have better adherence could be explained by the fact that these patients have easier access to healthcare facilities compared to those from rural areas. This finding could be supported by a study done by Kathie Walker, who found that patients who stayed far from the health facilities $(>10 \mathrm{~km}$ ) were significantly associated with poor compliance. ${ }^{6}$ There was no difference between men and women regarding their level of adherence, although an earlier study by Dorothy had revealed that men are more likely to be non-adherent compared to their female counterparts. ${ }^{7}$

Whether the lack of significant factors reflects a true lack of association, a limited time to follow up, or rather, the effect of a small sample size is uncertain from these results. Most of the studies done on this topic have not analyzed for these patient factors, making it rather a complex area to discuss. Nevertheless, these trends do identify subgroups that might be at increased risk of recurrent ARF and worsening of RHD through non-adherence. The commonest reason reported for non-adherence participants feel hassled about sticking medication(s) 90\%. This was closely followed by forget to take their medicine $(70 \%)$ and the fact that the patients cutback or stopped taking their medication (70\%). These factors have also been described by WHO expert consultation in Geneva. ${ }^{4}$ Similarly some reports also indicated that forgetting could be an import reason for missing medication. However, other factors of interest included respondents forget to bring when they travel or leave home, stopping their medication when they feel the disease is under control. These factors will form the basis for intervention in order to improve adherence among our patients.

\section{Conclusion:}

The public health dimension of Bangladesh is highly complex, with multifaceted risk factors contributing to chronic infectious diseases such as RHD. Based on the findings of the study, date of birth, gender, marital status, education, family size, duration of diagnosis were significantly or almost significantly associated with susceptibility to rheumatic heart disease in the adult population of Bangladesh. In order to reduce RHD burden in Bangladesh, ensuring universally accessible education is essential. Moreover, since patients with nutritional interventions and supplementation mandates, along with preventive measures against noncommunicable diseases, would be helpful, for reducing adults' chances of having RHD.

\section{Acknowledgements:}

All the authors acknowledge National center for the control of Rheumatic fever \& Heart diseases (NCCRF/HD) and the participants for providing the necessary information to conduct the study.

\section{Conflict of Interest - None.}

\section{References:}

1. Gewitz MH, Baltimore RS, Tani LY, Sable CA, Shulman ST, Carapetis J, et al. Revision of the Jones Criteria for the diagnosis of acute rheumatic fever in the era of Doppler echocardiography: a scientific statement from the American Heart Association. Circulation 2015; 131: 18061818.

2. Denny FW, Wannamaker LW, Brink WR, Rammelkamp $\mathrm{CH}$ Jr, Custer EA. Prevention of rheumatic fever; treatment of the preceding streptococcic infection. $J \mathrm{Am}$ Med Assoc 1950; 143: 151-153. 
3. Stollerman GH, Rusoff JH, Hirschfeld I. Prophylaxis against group A streptococci in rheumatic fever; the use of single monthly injections of benzathine penicillin G. $N$ Engl J Med 1955; 252: 787-792.

4. Carapetis JR, Steer AC, Mulholland EK, Weber M. The global burden of group A streptococcal diseases. Lancet Infect Dis 2005; 5: 685-694

5. Lawrence JG, Carapetis JR, Griffiths K, Edwards K, Condon JR. Acute rheumatic fever and rheumatic heart disease: incidence and progression in th Northern Territory of Australia, 1997 to 2010. Circulation 2013; 128: 492-501.

6. Parnaby MG, Carapetis JR. Rheumatic fever in indigenous Australian children. J. Paediatr Child Health 2010; 46: 527-533.

7. Rothenbuhler M, O'Sullivan CJ, Stortecky S, Stefanini GG, Spitzer E, Estill J, et al. Active surveillance for rheumatic heart disease in endemic regions: a systematic review and meta-analysis of prevalence among children and adolescents. Lancet Glob Health 2014; 2: e717-e726.

8. Harrington Z, Thomas DP, Currie BJ, Bulkanhawuy J. Challenging perceptions of non-compliance with rheumatic fever prophylaxis in a remote Aboriginal community. Med J Aust 2006;184(10):514-517.[PubMed]
9. Stewart T, McDonald R, Currie B. Acute rheumatic fever: adherence to secondary prophylaxis and follow up of Indigenous patients in the Katherine region of the Northern Territory. Aust J Rural Health 2007;15(4):234240. [PubMed]

10. Kholdebarin R, Campbell RJ, Jin YP, Buys YM. Multicenter study of compliance and drop administration in glaucoma. Can J Ophthalmol 2008; 43: 454-461. doi: 10.3129/i08-076. [PubMed][Cross Ref]

11. Boland MV, Chang DS, Frazier T, Plyler R, Friedman DS. Electronic monitoring to assess adherence with once - daily glaucoma medications and risk factors for nonadherence: The automated dosing reminder study. JAMA Ophthalmol 2014;132:839-844. [PubMed]

12. Dreer LE, Girkin C, Mansberger SL. Determinants of medication adherence to topical glaucoma therapy. $J$ Glaucoma 2012;21:234-240. doi: 10.1097/ IJG.0b013e31821dac86. [PMC free article] [PubMed][Cross Ref]

13. Welge-lussen U, Weis S, Yu AL. Assessing the adherence behavior of glaucoma patients to topical eye drops. Patient Prefer Adherence 2015;18:17-23. [PMC free article] [PubMed] 